\title{
Cost Parameters of Green Residential Buildings in Pune, India
}

\author{
Anshul P Gujarathi ${ }^{\text {a }}$ \\ B.N. College of Architecture, Pune. Karvenagar, Pune, India
}

\begin{abstract}
Various studies have been performed on cost impacts and impact parameters in Green Buildings against the conventional ones. Most of the studies include commercial buildings prioritizing energy and water related impacts while fewer studies are done on residential scale. This paper attempts to study the residential side of Green.
\end{abstract}

Green certification and rating programs define the greenness quotient for a project with their predefined parameters. These parameters and their standards can be linked directly for their cost impact. In India, Pune is one of the pioneer cities with respect to the number and coverage of green building footprint. All the pertinent ratings of the country appreciate its prominent presence in Pune city with the advantages of applicable municipal incentives.

This paper aims to determine and analyse the cost incremental factors for the certified green residential buildings in Pune against the conventional buildings. It will also determine the incremental percentage or the monetary value which impact the project cost.

For the study, certified green projects from Pune are considered with at actual data pertaining to the project. The analysis is aimed for the overall effective resultant of cost incremental or decremental factors with the cost benefit analysis. Further a factor analysis is carried out for a survey conducted for the buyers with their approach to green buildings and cost associated.

\section{Introduction}

The evolving concepts of sustainability today, are no more limited to a typical segment of people like green building consultants or the authorities preaching them. The thoughts have penetrated much deeper and every individual is aware of depleting resources and global warming disadvantages. From an office going individual to a house wife; from a school going child to a grandfather; all realize the importance of saving of water and resources. The global awareness spread has positively impacted overall sustainability scenario in the country and benefitting the blessed city of Pune. Pune claims the status of one of the leading real estate destinations in India [18]. Due to Mumbai proximity and its strategic location in the state, it is spreading on all sides for development.

With the advantage of educational hub there has always been a good demand for jobs in the city. With IT $\&$ ITES development the demand was higher which inflicted upon the residential demand in the main town. Industrial development along with the ancillaries manufacturing units majored the growth of the Pimpri Chinchwad [PCMC] region thus further increasing the residential demand. Studies by major giants in real estate industry also claim that Pune real estate market has expanded by $16.6 \%$ in the time span of one year i.e. from June 2011 to 2012. [19]. Prices have escalated by $14 \%$ with massive price gain in areas under Gram Panchayat. [12]

The resource strain inflicted by the construction industry alone, dedicated stakeholders play an important part in forward progress. Many organizations and associations have been created to help the building industry embrace sustainability both practically and theoretically stressing on the actual implementation of green building practices in construction [12]. With intend of branding and / or expediting the associated intricate processes, green certifications are being adopted by almost every developer in Pune city. Association of Municipal tax rebates have further added to the intent of going green, giving monetary gains to the developer and the end user. The degree of greenness is proportionally linked with the tax benefits which help in pushing the stakeholders going with premium ratings. On the other hand, there are few reservations realized with green buildings amongst which the cost factor remains at the acme. [19]

This study will enlist the parameters responsible for cost incremental or decremental factors which are

\footnotetext{
${ }^{\mathrm{a}}$ Corresponding author : anshulpgujarathi@gmail.com
} 
additionally associated due to a green rating. The post occupancy or operational stage is not considered for study.

\section{Environmental parameters - A brief: $2000-2013$}

The parameters for environment friendly constructional practises have been always a part of the bye laws and the literature of corporations. The environmental status reports have been a strong proof for the same. The parameters were never highlighted as a separate entity but always a part of the integrated construction process. The need for a recognised methodology and degree of greenness was realized and so the concept of green ratings was introduced in the country [2]. International protocols and growing awareness in the global scenario also created the need in the Indian market. The rating tool offered a similar concept which was associated with project branding and measurement of green status. The concept of green buildings picked up pace after year 2000 in India [7]. The authority organisations presented their voluntary assessment systems to the citizens which were propagating the green construction practices from design to operational phase. For its proliferation several offers and benefits including monetary benefits were attached to the rating systems. The globally recognised rating LEED made a way in India with its Green Homes rating which was further modified to Indian context by Confederation Of Indian Industry [CII]. The rating was termed as IGBC Green Homes, where IGBC is Indian Green building Council clearly highlighting the localised sense. Eco Housing India, IGBC Green Homes and Griha are the ratings that were presented to the city of Pune during the past decade. Environmental parameters influence the distribution, abundance and activity of animals and plants. Local meteorological conditions such as air temperature, rainfall or sunlight may affect the behaviour of terrestrial organisms, and water current, dissolved oxygen, suspended material and river bed topography may influence aquatic species. [12]-[19]

\section{Green building rating systems}

In India, there are rating systems like LEED, IGBC, Eco Housing and GRIHA. They have a predefined set of criteria that have intent towards direct applicable environment aspect with points against each of them. Few points are mandated while others are voluntary as per the choice of the project. Buildings are required to fulfill the defined criteria and achieve a certain number of points to be certified. In addition to these rating systems, there are codes that are applicable to defined projects. These codes are not mandated till date but might be a mandate to go with in near future. Energy Consumption Building Code [ECBC] has a direct implication with measurable energy savings. With all these guidelines there is National Building Code [NBC] which provide instructions on the energy consumption of buildings. All buildings in India need to comply with the guidelines set up by ECBC and the NBC.
We can define Green Buildings as structures that ensure efficient use of natural resources in construction. Use of eco friendly building materials, savings in water $\&$ energy and other resources with minimal generation of non-degradable waste are key parameters for green buildings. Further to the basic systems in the defined green way, technology support enhances the greenness quotient of the project. Technologies prove very helpful to help measure the actual savings that reflect in the system. Examples like efficient cooling systems with sensors that can sense the heat generated from human body and automatically adjust the room temperature, prove much more beneficial than only limiting to system installations, further saving energy. The same applies to the lighting systems too resulting in saving of energy against lighting. Green buildings have a smarter lighting system that automatically switches off when no one is present inside the rooms. Simple technologies like air based flushing system in toilets that avoids water use by $100 \%$, use of energy efficient LED's and CFL's instead of conventional incandescent lamp, new generation appliances that consume less energy, and many other options help in making the buildings green and make them different from conventional ones.

In Pune city, all the four rating systems are predominantly noted. Due to the applicable benefits to the region, the city experiences a large green building footprint in the country with LEED, IGBC and GRIHA combined footprint.

\section{Green building parameters}

There are several parameters on which a building is evaluated before being awarded with a final certification. The overall parameters can be categorized as following major heads:

\subsection{Efficiency of site selection and planning}

The site selection and planning section addresses the ecology and environment concerns related to residential construction and site development activities including the design of landscape.

\subsection{Water management}

Efficient water and waste water management for reducing water usage demand on fresh water sources is the prime focus. The residential sector is one of the significant water consumers, after agriculture. The certification parameters encourage water usage in a selfsustainable manner through reduce-recycle-reuse concept.

\subsection{Energy efficiency}

Reducing demand of conventional energy by optimization of building design and structure is the prime focus. Incorporating renewable sources of energy and renewable energy based systems such as solar water heater to reduce the use of conventional energy are evaluated and applied in the project under this head. 


\subsection{Materials}

Efficiency in selection of sustainable materials for construction and the technologies considered is evaluated.

\subsection{Indoor environmental quality}

Enhancement of indoor environment quality like indoor air and thermal quality is evaluated including daylight parameters.

\subsection{Innovation}

The credits that are performing exemplary in few of the above criteria can avail additional points under innovations. Also if the project attempts any beneficial activity that is not mentioned in the rating but that can help to prove positive benefit to the environment they can claim additional points under this head.

\subsection{Audit \& maintenance}

Optimization of operation and maintenance.

Table 1. Combined weight age of criteria

\begin{tabular}{|l|c|c|c|}
\hline \multicolumn{1}{|c|}{ FOCUS AREA } & IGBC & GRIHA & Combined \\
\hline $\begin{array}{l}\text { Building Planning \& Designing (AC/Non } \\
\text { AC) }\end{array}$ & $15 \%$ & $12 \%$ & $14 \%$ \\
\hline $\begin{array}{l}\text { Energy Efficiency (Lighting, HVAC, } \\
\text { Renewable) }\end{array}$ & $13 \%$ & $12 \%$ & $13 \%$ \\
\hline Construction Materials & $12 \%$ & $12 \%$ & $12 \%$ \\
\hline Indoor Environmental Quality & $11 \%$ & $11 \%$ & $11 \%$ \\
\hline Waste Management & $11 \%$ & $10 \%$ & $11 \%$ \\
\hline Innovations & $9 \%$ & $9 \%$ & $9 \%$ \\
\hline Water Efficiency & $7 \%$ & $7 \%$ & $7 \%$ \\
\hline Social Consideration & $7 \%$ & $7 \%$ & $7 \%$ \\
\hline Landscaping & $6 \%$ & $6 \%$ & $6 \%$ \\
\hline Site Selection & $4 \%$ & $6 \%$ & $5 \%$ \\
\hline $\begin{array}{l}\text { Preservation of Natural resources on } \\
\text { Site. }\end{array}$ & $4 \%$ & $5 \%$ & $5 \%$ \\
\hline Efficient Transportation System & $1 \%$ & $3 \%$ & $2 \%$ \\
\hline
\end{tabular}

To compare green and conventional buildings, major parameters that will be under consideration include those areas where the Green element shall make an impact. There are many parameters which will have common considerations as per the sanctioning mandates or by the environmental committee suggestive mandates. Only those parameters that are additional for green building will be accounted for this study [1]-[4].

\subsection{Case study analysis}

A brief survey was carried out for a sample of 150 where the preference of the developers and buyers was asked for the rating to be opted for while doing a green building.

Looking at the popularity of the ratings in the building sector in private and government sector both, IGBC and GRIHA prove to make a mark in the Indian industry. Similarly for the city of Pune both these ongoing ratings are prominent and exceed the footprint than other ratings.

We can thus study the two prominent ratings in Pune, i.e. IGBC and GRIHA; for the preferential weight age catered to each of the criteria as defined by Green norms. As per the defined categories of the ratings, the following table is identified with the weight age in terms of points given to each criterion under that category.

From the above tables it can be realized that the prevalent rating systems in India give most priority to the Building design and comfort parameters. Average high priority is for the materials and water and waste management is given considerable weight age. Significant points lie with the main credits but the supporting credits are designed in such ways that they have great influence on main points. With their minor number they can assume greater impact on main points further adding green quotient to the project. Further detailed analysis for these parameters is carried out on the basis of their cost impact against each of the criteria.

Cost impactive parameters for green and conventional buildings

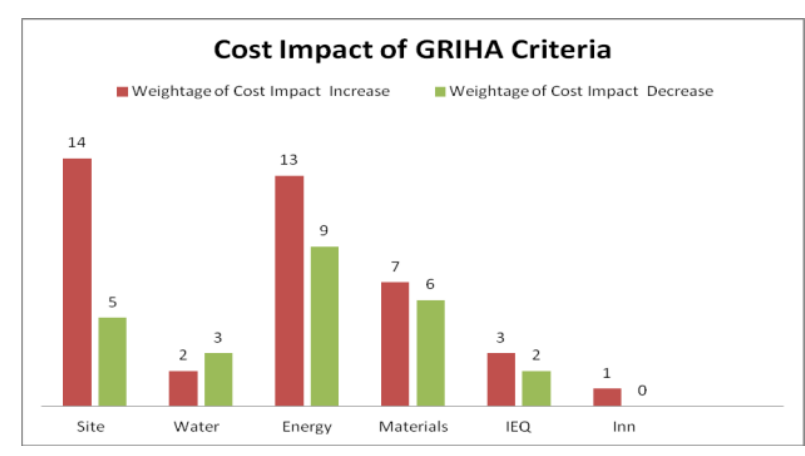

Figure 1. cost impact - Griha.

In residential sector for most preferred ratings of IGBC \& GRIHA many projects can be identified that have reached a benchmark for study. Considering the parameters of conventional and green buildings, a detailed study is carried out for GRIHA and IGBC criteria to understand the impactive credits for the entire project. The cost impact shall only be considered for first costs impact, either increasing or decreasing cost for conventional against green building [3].

The overall study has been divided in two parts. The first part of the study is the identification of the variables of the cost parameters for conventional against green. Whilst the second part is the actual set of certified buildings are studied for the impacted cost. Here the detailed checklist for both rating systems is analyzed for the first cost impact that is probable for both the conventional and green [5].

Below analyses helps us to identify how the cost increment or decrement is impacting the green against the conventional case. This analysis is made against each sub part of the criteria for both ratings and segregated under heads as mentioned in the figures below.

It is noted that the parameters related to site and energy show a significant increase in cost parameters with green attempted criteria whilst there is also a significant decrease observed with the parameters of 
materials specifically under the structural head. With the increase in cost there is a high scope for cost decrease also with the attempt of right technology and correct material selection. Simultaneous decrease is also observed under the water and site credit with the responsible parameter of landscape.

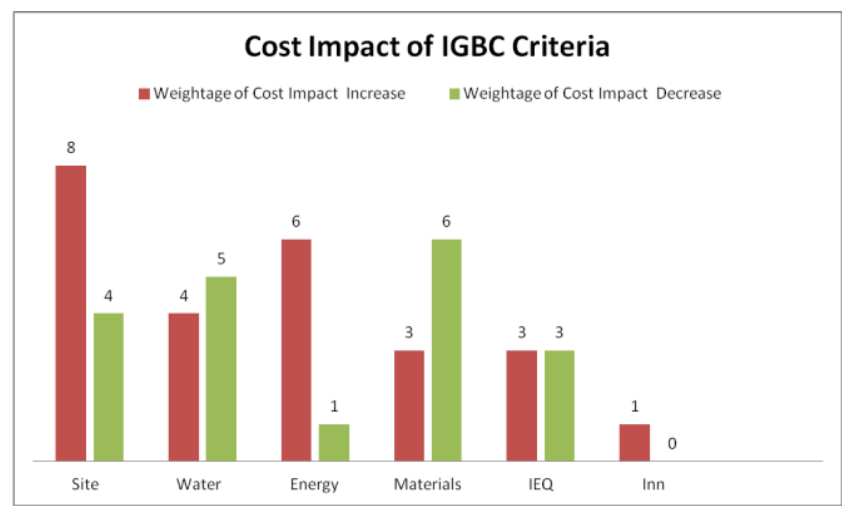

Figure 2. Cost impact IGBC.

\subsection{Ranking of the activities based on their costs}

For each of 15 sites, activities were arranged in the descending order based on the cost the activities. The top ten activities were assigned the ranks. Then the average rank was computed for each activity. The top ten expensive activities of each site were identified. The activities were rank based on the proportion of sites listed a particular activity to the total sites carried out that activity. E.g. Solar water heater was provided on nine sites and for all those sites this activity was identified as top ten expensive activities.

\section{Cost impact parameters - discussion}

An important limitation of all economic research on this topic is the absence of data directly linking specific resources and investments in construction to measures of energy efficiency or sustainability. Some evidence has been gleaned from experiments in construction and the subsequent operation of actual green buildings, but these are based on very small samples.

Research on climate change suggests that small improvements in the sustainability of the existing building stock can have large effects on energy efficiency in the economy. Increased awareness of global warming and the extent of greenhouse gas emissions in the real estate sector have increased attention to green building. [1]-[8] Measured attributes of sustainability and energy efficiency are incorporated in property rents and asset prices, and this seems to persist through periods of volatility in the property market. These developments will affect the existing stock of noncertified office buildings [1]. The findings already suggest that property investors attribute a lower risk premium for more energyefficient and sustainable commercial space. Rated buildings may provide a hedge against higher energy prices, but also against the shifting preferences of both tenants and investors with respect to environmental issues. Increasing market awareness of climate change and rising energy costs can only increase the salience of this issue for the private profitability of investment in real capital.

Green Buildings have shown a gradual growth in past few years and related thoughts like increase in cost due to green parameters have often created the hindrance for the promotion of green buildings [4].

The above study gives us the variables for cost impact on both positive and negative grounds.

The Cost Positive Impacts - These set of variables prove beneficial when green compared to conventional case. The overall savings shall be anticipated with these criteria.

a) Choosing a brown field or a contaminated site might prove indirectly beneficial as it can be attained at a lower cost compared to market price.

b) Existing amenities can prove beneficial to the end users and give them an indirect benefit of fuel savings.

c) Use of AAC blocks or light weighted blocks for structural construction. This will reduce the overall load on structure thus anticipating huge savings in material and structural work.

d) Landscape norms and methods have a cost positive impact.

e) Reuse of materials and recycling will reduce the use and need for virgin materials and prove cost efficient.

f) Use of low energy materials can reduce the first cost of purchase.

g) Harvesting rain water can prove beneficial as the overall water use can be reduced thus reducing the cost associated with that.

h) Reuse of treated water for flushing can reduce the need of fresh water and new water use.

i) Proper site management can save $5 \%$ to $10 \%$ of material wastage thus saving on associated material cost.

j) Use of water based enamel for paints prove less costly compared to oil based.

The Cost Negative Impacts - These set of variables prove cost impactive when green compared to conventional case. The overall savings shall be anticipated at the later stages in the long run but for first costs they prove costly.

a) As per design and norms, dedicated parking and reduced hard areas in landscape may affect the overall area distribution that can be directly associated to the cost.

b) Site related maintenance activities and labour camp involve regular check and efforts. This is an ongoing cost to the project.

c) Use of mechanical and electrical appliances including pumps and motors as per the prescribed norms prove costly. Here the long term savings anticipated are not considered though they prove long terms beneficial in terms of both running and maintenance.

d) Specialty fixtures for water and accessories claim to be costly.

e) Envelope and the fenestration materials as prescribed by the rating norms. 
f) Features like electric charging points and changing rooms or toilets may prove cost intensive.

g) Use of specialty products like certified wood or hybrid generators, etc. are cost intensive.

The overall comparison of green and conventional cannot be justified for cost increment or decrement unless actual projects are studied for. Since every project has a separate design brief and differently prescribed amenities, the comparison can never be on common grounds unless common case created for the same. For further study certified buildings were commonly clubbed for IGBC and GRIHA categories and separately studied for the parameters and further clubbed together with mean for analysis.

\section{Cost analysis - case studies}

The identified variables in the above study were further applied to a group of certified buildings which were studied for comparison of their own conventional and green case for cost impacts. As a standard the conventional case was considered as the case without the green implication for the same project in similar situation. Thus cost impact was taken nullified for that particular credit and the cost for conventional was considered less than the value against the green case. Similarly the cost positive areas were considered for the value which was reduced from the conventional case. The overall impact is the resultant value that is notified in the table. The cost data collected for 15 sites were analyzed in great detail to understand the difference in conventional and green cost of the construction. Also, the activities which contribute in these differences were studied and presented in the following section.

Table 2 presents the details of the cost data based all 15 sites under study. The conventional cost of the sites ranged 1,021 - 1,402 Rs./sq.ft. with the mean Rs. 1,238 [ \pm 113$]$. Whereas, the mean green cost of the sites were Rs.1,253 [ \pm 117$]$ per sq.ft. It was observed that the green cost of the sites were higher than the conventional cost. On an average there was an increase of 14.80 Rs./sq.ft in green cost, which accounted for $1.2 \%$ increase over conventional cost.

However, the mean percent increase in green cost over conventional cost was highest for medium projects $[1.6 \pm 0.6]$ followed by small projects $[1.3 \pm 0.2]$. Percent increase in green cost for large projects was only $0.6[ \pm$ 0.3 ], which was less than half of the increased observed in small and medium projects [Figure 5]. The difference in green cost of projects across the groups was statistically significant as indicated by the test statistics of non-parametric Kruskal Wallis Test.

Table 2. Average building conventional cost and green cost

\begin{tabular}{|l|l|l|l|l|}
\hline Statistics & $\begin{array}{l}\text { Conventional } \\
\text { cost } \\
\text { [Rs./sq.ft.] }\end{array}$ & $\begin{array}{l}\text { Green cost } \\
\text { [Rs./sq.ft ] }\end{array}$ & $\begin{array}{l}\text { Difference } \\
\text { in cost } \\
\text { [Rs./sq.ft] }\end{array}$ & $\begin{array}{l}\% \\
\text { increase } \\
\text { in cost }\end{array}$ \\
\hline Mean & 1,238 & $1,253^{*}$ & 14.80 & 1.2 \\
\hline $\begin{array}{l}\text { Standard } \\
\text { deviation } \\
\text { of mean }\end{array}$ & 113 & 117 & 13.10 & 1.0 \\
\hline Range & $\begin{array}{l}1,021 \\
1,402\end{array}$ & $\begin{array}{l}1,026 \\
1,419\end{array}$ & $\begin{array}{l}1.25 \\
53.1\end{array}$ & $\begin{array}{l}0.1 \\
4.23\end{array}$ \\
\hline
\end{tabular}

$\mathrm{n}=15$

Non-parametric analog of paired t-test i.e. Wilcoxon Signed Ranks Test statistics $[\mathrm{z}=3.408, \mathrm{p}=0.001]$ indicated that the difference between conventional cost and green cost was statistically significant.

For every typology the premium rated project shows higher increase in cost while the projects with two star or so show very negligible cost raise. If proper factor for maximum cost contribution is identified for the premium rated projects against the points earned definitely the gap can be bridged and the cost can be nullified maintaining the same point cadre.

\section{Factor Analysis}

Table 3. Factor tests.

$\mathrm{KMO}$ and Bartlett's Test

\begin{tabular}{|ll|l|}
\hline Kaiser-Meyer-Olkin Measure of Sampling Adequacy. & .675 \\
& Approx. Chi-Square & 2798.714 \\
Bartlett's Test of Sphericity & df & 276 \\
& Sig. & .000 \\
\hline
\end{tabular}

The opinions of the buyers about the green buildings were collected using 24 items questionnaire. The response format for each statement was the standard Likert 5-point scale. A factor analysis with varimax rotation was used to create the factor structure of the 24 items included in the questionnaire. Factor analysis was carried out using the maximum likelihood method with pair wise deletion.

Data adequacy for the spiritual climate inventory was checked with the KMO test, the value of which is 0.675 [Table 3]. A value is higher than 0.5 which indicated that the data is sufficient for factor analysis. Chi square value 2798.714 at 276 degrees of freedom was significant at less than 0.0001 level of significance. The significant value of Chi Square test indicates the acceptability of eight factor solution. The eight factor solution proposed by them holds valid on the current sample.

The factors were rotated by an orthogonal transformation [varimax] to achieve a simpler structure with greater interpretability. Data were aggregated in three factors with Eigen values greater than 2 and explained about $47.7 \%$ of the variance. Items with Factor loadings $>0.55$ were used to define factors [Table 4]. The factor score coefficients were estimated by the regression method, which produces uncorrelated scores with a mean of 0 and a standard deviation of 1 .

Table 4. Factor loading matrix.

\begin{tabular}{|l|l|l|l|}
\hline \multirow{2}{*}{ ITEMS } & \multicolumn{3}{|c|}{ COMPONENT } \\
\cline { 2 - 4 } & $\mathbf{1}$ & $\mathbf{2}$ & $\mathbf{3}$ \\
\hline $\begin{array}{l}\text { Green building saves energy \& } \\
\text { resources at individual level. }\end{array}$ & .878 & .081 & .053 \\
\hline $\begin{array}{l}\text { Today's residential complexes should } \\
\text { be mandatorily "Green". }\end{array}$ & .854 & .024 & -.193 \\
\hline $\begin{array}{l}\text { Pay back calculation in green building } \\
\text { is essential. }\end{array}$ & .829 & -.281 & -.120 \\
\hline
\end{tabular}




\begin{tabular}{|c|c|c|c|}
\hline $\begin{array}{l}\text { Studies related to COST of green } \\
\text { buildings can help the reservation } \\
\text { towards the green approach }\end{array}$ & .782 & .010 & .013 \\
\hline $\begin{array}{l}\text { "Green building "refer to a] Energy \& } \\
\text { Cost saving b] Social welfare c] } \\
\text { Environment protection }\end{array}$ & .761 & .004 & -.089 \\
\hline $\begin{array}{l}\text { Green buildings help for climate } \\
\text { impact mitigation in the long term. }\end{array}$ & .718 & .439 & -.067 \\
\hline $\begin{array}{l}\text { COST one of the major hindrances } \\
\text { that prevent the developers from } \\
\text { taking a green approach. }\end{array}$ & .705 & .182 & .204 \\
\hline $\begin{array}{l}\text { Green buildings benefits to overall } \\
\text { society, a region \& improves the } \\
\text { quality of life. }\end{array}$ & .658 & .207 & -.125 \\
\hline $\begin{array}{l}\text { Early initiation of green strategies } \\
\text { result in COST benefitting structure }\end{array}$ & .645 & .019 & .191 \\
\hline $\begin{array}{l}\text { Municipal Corporations } \\
\text { incentivize Green buildings }\end{array}$ & .580 & .096 & .074 \\
\hline $\begin{array}{l}\text { Maintenance of Green residential } \\
\text { buildings are costly compared to } \\
\text { conventional ones. }\end{array}$ & -.746 & .260 & .065 \\
\hline $\begin{array}{l}\text { Green buildings help in gaining } \\
\text { monetary benefits to the end-users i.e. } \\
\text { residents, in the long run. }\end{array}$ & .115 & .600 & -.080 \\
\hline $\begin{array}{l}\text { Green building materials can } \\
\text { influence the cost of the project } \\
\text { negatively. }\end{array}$ & .013 & .581 & .436 \\
\hline $\begin{array}{l}\text { COST is the utmost important factor } \\
\text { for a green building. }\end{array}$ & .566 & -.686 & -.027 \\
\hline $\begin{array}{l}\text { Payback calculation is reliable to a } \\
\text { satisfactory extend. }\end{array}$ & .016 & -.724 & -.152 \\
\hline $\begin{array}{l}\text { Services play a very important role in } \\
\text { Green buildings and can save on huge } \\
\text { resources. }\end{array}$ & .119 & -.248 & .745 \\
\hline $\begin{array}{l}\text { Green building certification programs } \\
\text { define a totality green building. }\end{array}$ & .042 & .081 & .655 \\
\hline $\begin{array}{l}\text { The implementation of green features } \\
\text { is cost intensive. }\end{array}$ & -.040 & .029 & .646 \\
\hline $\begin{array}{l}\text { Green project should be preferred for } \\
\text { stay than conventional one. }\end{array}$ & -.174 & .269 & .538 \\
\hline $\begin{array}{l}\text { Experience of stakeholders with } \\
\text { Green buildings result in COST } \\
\text { saving. }\end{array}$ & .541 & .248 & -.528 \\
\hline $\begin{array}{l}\text { Energy efficiency \& Water Savings } \\
\text { are related to COST savings. }\end{array}$ & .540 & .300 & .463 \\
\hline $\begin{array}{l}\text { Green } \begin{array}{l}\text { Building } \\
\text { guidelines improve the envification } \\
\text { quality of the project. }\end{array} \\
\text { quent }\end{array}$ & .295 & .492 & -.104 \\
\hline $\begin{array}{l}\text { Green Growth is related to Economic } \\
\text { growth in real estate }\end{array}$ & -.417 & .231 & -.232 \\
\hline $\begin{array}{l}\text { Overall awareness \& green education } \\
\text { is the key for the Green project }\end{array}$ & .553 & .044 & -.244 \\
\hline
\end{tabular}

The factors extracted from the analysis were label based on the items which loaded [loading $>0.05$ ] on the factor. Internal consistency of these three sub-scales was assessed by calculating Cronbach's alpha. High values for Cronbach's alpha obtained during analysis indicated good internal consistency of the items in the scale.

Table 5. Factor details Cronbach's alpha.

\begin{tabular}{|l|l|l|}
\hline Factor no. & Factor Label & alpha \\
\hline Factor 1 & Cost Conscious & 0.837 \\
\hline Factor 2 & Environment Conscious & 0.673 \\
\hline Factor 3 & Quality of life & 0.636 \\
\hline
\end{tabular}

\section{Factor scores}

The factor score coefficients were estimated by regression method, which produces uncorrelated scores with a mean of $0 \&$ a standard deviation of 1 .
Factor scores are composite variables which provide information about an individual's placement on the factor[s]. Higher the scores, higher will be the agreement with the factor.

The distribution of the respondents on three factors is given in following table.

Table 6. Factor outcomes.

\begin{tabular}{|l|l|l|l|}
\hline No. & Factors & Frequency & Percent \\
\hline 1 & Cost Conscious & 64 & 42.1 \\
\hline 2 & Environment Conscious & 49 & 32.2 \\
\hline 3 & Quality of life & 39 & 25.7 \\
\hline & Total & 152 & 100.0 \\
\hline
\end{tabular}

\section{Conclusion}

Green Buildings can be made cost neutral with the right implementation of strategy at the correct aspect. Maintaining the balance between the cost raise and cost decrease a neutral approach can be attained where in a premium rating at no additional cost can be realized. The benefits on the life cycle performance are the added advantage for the project with long terms savings. Every activity associated with green is for the wider cause of the sustainable parameter and always proves beneficial to every stakeholder directly or indirectly.

A sufficient economic return on energy-efficiency investments is crucial for the sustainable development of the green building industry. The concern of environment and sustainable development has been increased recently. These problems force the countries to adopt a number of policies that enhance energy efficiency and apply baseline parameters in accordance with international standards. Green building has now become a forefront of sustainable development in this century that takes the responsibility for balancing long-term economic, environmental and social health. It offers an opportunity to create environmentally efficient buildings by using an integrated approach of design.

\section{References}

1. Cost of Green Revisited : Davis Langdon, Reexamining the Feasibility and Cost Impact of Sustainable Design in the Light of Increased Market Adoption, (July 2007)

2. The Economics of Green Building: Piet Eichholtz, Nils Kok, John M. Quigley, USGBC LEED Journal, (August 2010)

3. What Does Green Really Cost: Peter Morris, Davis Langdon, The Green issue Feature, PREA Quarterly, (Summer 2007)

4. Managing Costs of Green Buildings: Geof Syphers, Mara Baum, Darren Bouton, Wesley Sullens, State of California's Sustainable Building Task Force, the California State and Consumer Services Agency and the Alameda County Waste Management Authority, (October 2003)

5. Costing Green: A Comprehensive Cost Database and Budgeting Methodology, Lisa Fay Matthiessen, Peter Morris, Davis Langdon, (July 2004) 
6. Environment report highlights the negative side of Pune growth story

7. Radheshyam Jadhav, TNN, 04.58am IST (Jul 27, 2011)

8. Tradition and modernity subtly synchronised in Pune

9. Presidency Pune District, XVIII, Parts I, II, III, Pune.

10. Government of India, Gazetteer of Bombay State District (1954)

11. Series Vol. XX, Pune.

12. A Study of Residential Housing Demand in India; Online at http://mpra.ub.uni-muenchen.de/9339/

13. MPRA Paper No. 9339, posted 29. June 2008 02:55 UTC
14. City of Pune, An M.E. Thesis submitted at Government College of Engineering, Pune.

15. Sonawani, A., Haravalele Pune, Purva Publications, Pune (1998)

16. Speiregen, P., Urban Design: The Architecture of Towns and Cities, McGraw-Hill Book Company, New York (1965)

17. Pandya, Y, Housie, Architecture + Design, XVI, 5 (1999) pp. 43-47.

18. Pune Municipal Corporation, Development Plan of Pune, Pune Municipal Corporation, Pune (1991)

19. www.pcmc.gov.in 